\title{
Development of an Academic Course in Person-Centred Care for Students in Higher Education: Teachers' Perspectives
}

\author{
Kristina Rosengren $\mathbb{D}^{1,2}{ }^{1,2}$ Louise Danielsson, ${ }^{3}$ Inger Jansson, ${ }^{1}$ and Catarina Wallengren $\mathbb{D}^{1,2}$ \\ ${ }^{1}$ Sahlgrenska Academy, Institute of Health and Care Sciences, University of Gothenburg, Gothenburg, Sweden \\ ${ }^{2}$ University of Gothenburg Centre for Person-Centred Care (GPCC), Gothenburg, Sweden \\ ${ }^{3}$ Department of Health and Rehabilitation, Institute of Neuroscience and Physiology, University of Gothenburg, \\ Gothenburg, Sweden \\ Correspondence should be addressed to Kristina Rosengren; kristina.rosengren@gu.se
}

Received 2 August 2018; Accepted 17 September 2018; Published 17 October 2018

Academic Editor: Gwo-Jen Hwang

Copyright (C) 2018 Kristina Rosengren et al. This is an open access article distributed under the Creative Commons Attribution License, which permits unrestricted use, distribution, and reproduction in any medium, provided the original work is properly cited.

\begin{abstract}
Few studies describe the development of academic courses with interprofessional perspectives. Therefore, the aim of this study was to describe teachers' experiences with developing an academic course in person-centred care (PCC). Data collection was divided into three parts: (1) written material/documentation describing the process (text and pictures, 16 meetings), (2) SWOT analysis in relation to being a lecturer $(n=7)$, and (3) interviews with the lecturers $(n=4)$. The data were analysed using mixed methods, descriptive statistics (1) and qualitative content analysis (2-3). The results are presented in three categories (Co-creating a pilot course, Challenges of managing unfamiliar knowledge, and Wanting to understand new educational approach). This study highlights three challenges: (1) unfamiliarity with the field of person-centred care and selected educational activities and teaching skills; (2) unfamiliar colleagues, which delayed partnership efforts; and (3) limited experience working with other lecturers in light of the institute's structure and routines. However, these challenges served as both barriers and facilitators; the lecturers developed knowledge and experiences from collaborations (educational and/or content skills/knowledge) focusing on resources and skills.
\end{abstract}

\section{Background}

Person-centred care (PCC) is an approach that guides staff and students to focus on patients' resources and needs. In clinical practice, the approach is transformed and applied by the following actions: (1) listening to patients' narratives, taking part in them, and trying to understand them; (2) collaborating with patients to determine the best way to implement care, treatment, and rehabilitation (based on experiences and evidence); and (3) reaching agreements and documenting them in a health plan that is transparent for all involved [1]. Research has shown that these actions improve patients' quality of life $[2,3]$ and the discharge process [4] as well as metabolic control and self-efficacy [5, 6]. Furthermore, studies show such efforts decrease patients' fatigue [5] and uncertainty [7], which results in lower costs $[8,9]$ due to shorter hospital stays [3, 10, 11]. Moreover, staff report higher job satisfaction, a friendlier working environment, and reduced conscience stress when person-centred care is implemented [12-15]. At present, whether a PCC approach is implemented in clinical practice is linked to the attitudes of staff (interest in PCC), the presence of a strong medical tradition, and time constraints $[10,14,16-18]$.

Furthermore, the staff's knowledge, values, commitment, attitudes, and actions affect students' learning process $[19,20]$. For example, research $[21,22]$ shows that students are aware of PCC; however, the application of PCC is limited because their clinical supervisors use the approach insufficiently. Universities worldwide discuss how to implement PCC in their educational programmes [23, 24], and some have already implemented aspects of PCC, but not whole courses, in health-care education [21, 25]. Other studies describe how students support PCC education that uses pedagogic strategies such as role modelling, simulation, 


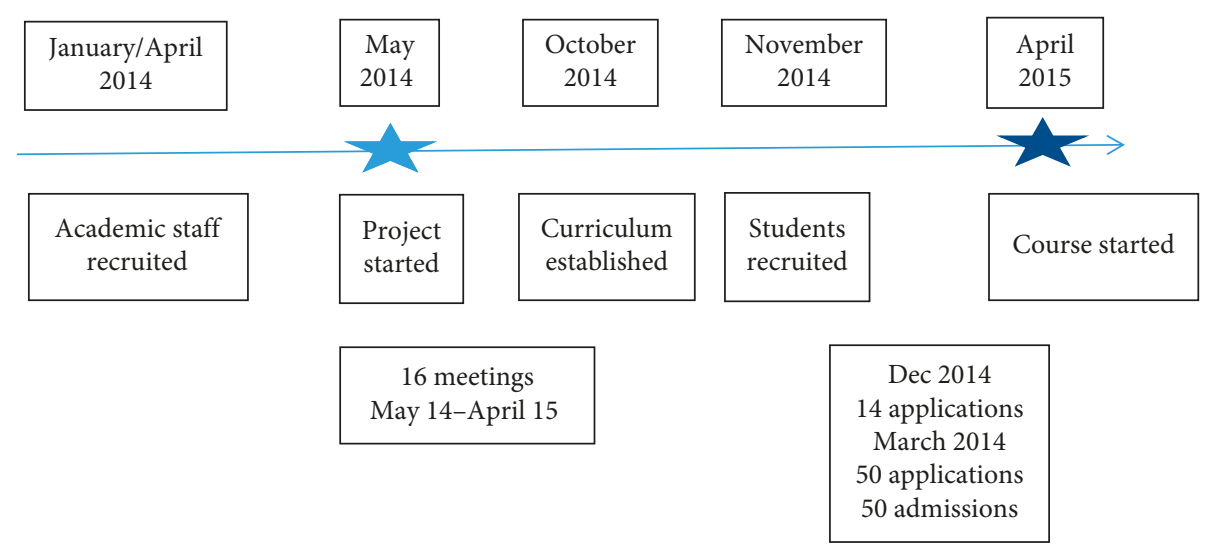

Figure 1: Structure and timetable of the development process.

and meeting with patients [26] and the development, implementation, and evaluation of PCC courses [27]. However, there are few studies describing the development of an academic course in PCC involving students and teachers from multiple disciplines to bridge the gap between professions and between academics and clinical practice. Therefore, the current paper intends to improve knowledge regarding the development of PCC in higher education. The aim of this study was to describe teachers' experiences in developing an interprofessional academic course in PCC at a Swedish university.

\section{Methods}

2.1. Development Process. The current study was grounded in a two-step project (We Educate Care, Figure 1) at Gothenburg University (38 000 students and 6000 staff members), located in western Sweden [28]. The personcentred care course within the health and social care was worth 7.5 credits and was initiated at both the central and local levels of the university. In the first step, a steering group was established that included educational leaders from the following departments: medicine, neuroscience, physiology, and nursing. The vice dean of Sahlgrenska Academy and researchers from the Pedagogical Development and Interactive Learning Unit and the Centre for Person-Centred Care (GPCC) were also included in the development process. In step two, both teachers $(n=7)$ and students $(n=3)$ from the abovementioned institutions were selected to develop competence in PCC and the planned pedagogic methods and then design an interprofessional academic course in PCC (second cycle).

Faculty development is described as efforts to support the development of faculty members' roles, knowledge, and skills in a specific area [29]. In the current study, improvements in teachers' knowledge and skills regarding PCC and related teaching methods were based on the same assumptions as person-centred care, as described by Ekman et al. [1]. The starting point is the teacher's capabilities, that is, resources (will, wishes, responsibilities, communication, narratives, actions, etc.) and needs (content, pedagogic methods, and learning style), as described by [30]. To facilitate the development of knowledge and skills in PCC as well as teaching methods, teachers' experiences and competencies needed to be challenged, utilized, and interwoven with new experiences built on evidenced-based knowledge (PCC, pedagogic methods). Three routines were used: (1) dialogues [31] regarding teachers' resources and needs in relation to PCC and pedagogic methods; (2) co-creative processes, such as learning groups [32]; and (3) the use of a web-based learning management system (http://pingpong. se) to document the course material. The course, called Person-Centeredness in Health Care and Social Sciences (7.5 credits), was developed collaboratively as a cross-academy course at the advanced level (second circle), and the syllabus contained eight learning goals to enable students' understanding, knowledge, and skills on the personal, partnership, narrative, and documentation levels [1]. Furthermore, flipped classrooms [33] and blended learning [34] were chosen as pedagogical methods by the teachers.

\subsection{Data Collection}

A convenience sample using mixed quantitative and qualitative methods was used [35]. The inclusion criteria were lecturers at University of Gothenburg involved in developing an interprofessional academic course in personcentred care for students in higher education. Data collection was divided into three parts: (1) written material/documentation describing the process (text and pictures collected over 16 meetings, descriptive statistics), (2) SWOT analysis [36] in relation to the staff $(n=7$, strengths-weaknesses-opportunities-threats), and (3) interviews with the staff ( $n=4$, content analysis). All the data were collected during the development process of the project (We Educate Care) in May 2014 to April 2015 (Figure 1).

(1) A total of 16 meetings of seven lecturers (women, aged 22-68 years) with master's or doctoral degrees (medicine, nursing, occupational therapy, pedagogic, and physiotherapy) and 2-40 years' experience in health care and/or education were included in the first part of the data collection. (2) SWOT analyses were performed in March 2015 to consider the strengths, weaknesses, opportunities, and threats related to being a teacher $(n=7)$. (3) The final 
TABLE 1: Example of content analysis of content into subcategories that formed a category.

\begin{tabular}{|c|c|c|c|c|}
\hline Meaning unit & Condensed content & Coding & Subcategory & Category \\
\hline $\begin{array}{l}\text { I think it is, now that I have } \\
\text { extended myself or read a lot } \\
\text { of literature on person- } \\
\text { centeredness, it is obvious that } \\
\text { we should work this way, but } \\
\text { in the beginning, when we } \\
\text { presented our own efforts } \\
\text { towards person-centeredness, } \\
\text { I felt a little bit frustrated } \\
\text { because it was very hard for } \\
\text { me to understand the } \\
\text { philosophy.... It may be } \\
\text { because I'm not used to } \\
\text { reading that kind of } \\
\text { literature... In education for } \\
\text { physicians, we are very fact- } \\
\text { oriented; it should be short } \\
\text { and concise. . and it was } \\
\text { really hard to understand }\end{array}$ & $\begin{array}{c}\text { Extended myself, read } \\
\text { literature on person- } \\
\text { centeredness, obvious we } \\
\text { should work this way, } \\
\text { beginning frustrated, very } \\
\text { hard understand philosophy, } \\
\text { not used to reading literature, } \\
\text { physicians very fact-oriented, } \\
\text { short/concise }\end{array}$ & $\begin{array}{l}\text { Diversity of } \\
\text { perspectives }\end{array}$ & $\begin{array}{l}\text { Challenges of managing } \\
\text { unfamiliar knowledge }\end{array}$ & $\begin{array}{c}\text { Co-creating an } \\
\text { interprofessional academic } \\
\text { course }\end{array}$ \\
\hline
\end{tabular}

I think it was just that these, we applied these models, the methods. You should read or get to know the material before you attend group meetings, and that made it possible. Then, when you met, you could - you got a deeper understanding and could spend time on concepts instead of clarifying them. This allowed you to discuss and immerse yourself in the

Applied these models, methods, read to know material before group meetings, deeper understanding, spend time on concepts instead clarifying, allow discussion, immersion in the subject
Responsibility Wanting to understand a new educational approach subject

The emerging findings are illustrated with quotes.

data collection step was performed in May 2015 and included interviews (in Swedish) with the teachers $(n=4)$. The interviews lasted 30-60 minutes and were performed individually, recorded, and then transcribed verbatim. The interviews started with background questions regarding age, education, employment, and experiences in health care. They then focused on three perspectives: the content of the person-centred care course, the development of course material (syllabus, study guidelines, assessments, and examinations), and the use of pedagogical methods (flipped classroom and blended learning).

\subsection{Data Analysis}

We used mixed methods [37], descriptive statistics, and qualitative content analysis to increase our understanding of the teachers' views and thoughts regarding developing an interprofessional academic course in person-centred care for students in higher education. This method showed conflicting opinions and unsolved issues regarding the meaning and use of concepts, procedures, and interpretation. Content analysis illustrates the use of concepts related to the research procedure to achieve trustworthiness in terms of credibility, dependability, and transferability [38]. Since research relies on trustworthiness, transparency, verification, and reflexivity and is "informant-driven," this design can be helpful when developing insightful and artful interpretations within higher education [35].

The data were analysed using descriptive statistics such as percentages (documentation of meetings) and manifest qualitative content analysis (SWOT analysis and interviews) in a step-by-step procedure [38]; the data were extracted and brought together into one text and then divided into meaning units that were condensed. Examples of meaning units, condensed meaning units, and codes are shown in Table 1. The texts were read to acquire a first impression of the content regarding developing an interprofessional academic course in PCC. The manifest analysis addressed questions regarding the teachers' experiences and was performed in the following steps: (1) The written words were read and reread to obtain an understanding of and familiarity with the text regarding developing a course in PCC. (2) Meaning units (words, sentences, or paragraphs) corresponding to the content areas were selected for (a) PCC-related content and (b) pedagogical issues and interprofessional work. The unit of analysis in this text addressed various aspects of PCC and blended learning. 


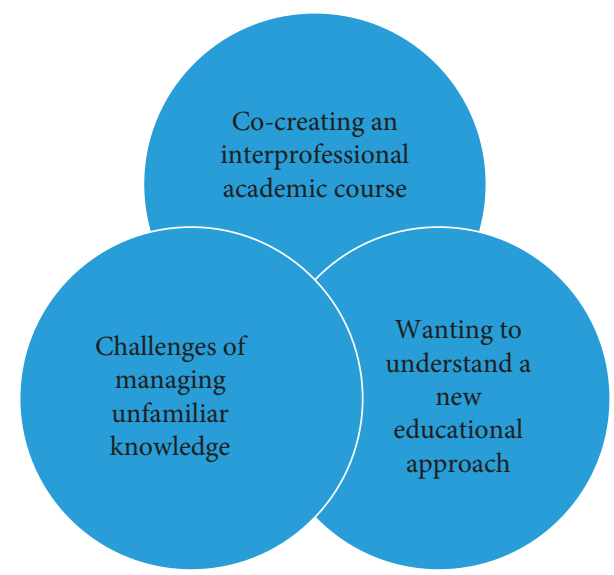

FIgURE 2: The categories generated by the results.

(3) Each condensed meaning unit was abstracted into a description of the processes of developing courses in higher education. Reflection and discussion resulted in agreement between two of the researchers (CW and KR) regarding how to sort codes. The whole context was considered, and the meaning units were labelled with 135 codes. (4) Finally, the various codes were compared based on their differences and similarities and were sorted into three categories: "Cocreating an interprofessional academic course," "Challenges of managing unfamiliar knowledge," and "Wanting to understand a new educational approach."

\subsection{Ethical Considerations}

No ethical approval was used because of Swedish rules and guidelines $[39,40]$ for research when teachers are included in data collection. However, respect for the individuals was a main concern during the study. All the participants were informed of the voluntary nature of participation and consented to participate in the study, knowing that they had the right to withdraw at any time and that their answers would be kept confidential. In addition, data analysis followed a scientific systematic analysis to ensure the trustworthiness of the results. Ethical guidelines for human and social research were considered throughout the study [40].

\section{Results}

The results yielded three categories: "Co-creating an interprofessional academic course," "Challenges of managing unfamiliar knowledge," and "Wanting to understand a new educational approach." The combination of the teachers' experiences and knowledge regarding PCC and education was described as significant for co-creating an interprofessional academic course. The categories are presented in Figure 2.

\subsection{Co-creating an Interprofessional Academic Course.} The category "Co-creating an interprofessional academic course" was described in terms of structure, openness to new perspectives, and the challenges of making joint decisions in collaboration with interprofessional colleagues.
The beginning of this category focused on the descriptive aspect of the data and the structure of project (We Educate Care) and can be described in four phases: getting to know each other, deepening and designing, forced resting, and completing the course material. The first phase, getting to know each other, created partnerships among the informants and accounted for $19 \%$ of the project time. The project group's resources and abilities regarding personcentred care and teaching skills resulted in shared decision-making during the development phase of the course. The second phase, deepening and designing, accounted for $25 \%$ of the project time and included knowledge skills regarding person-centred care (resources: narrative, partnership, and documentation) and educational approaches/flipped classroom and blended learning (syllabus, web-based learning platform, and recording teaching materials) and their implementation. The third phase, forced resting, accounted for $44 \%$ of the project time and comprised waiting for external actors during such events as advertising and recruiting students to the course. The last phase, completing the course material, comprised $12 \%$ of the project time and involved concrete planning before the first day of the course (study guidelines, assessments, examinations, teamwork, and lecturing). The total time allotment for the course was 1210 hours and included all participants involved in the project.

The following aspects of the results focus on the teachers' experiences in the development of the PCC course. The informants indicated in the interviews that it takes courage to develop an interprofessional course regarding personcentred care in higher education. They emphasized that courage included other colleagues' experience and knowledge of health care and/or co-creating interprofessional academic courses, which added value for them.

And actually, let someone else; do not be like, "No, but we have always done it this way," and "This is good" and "How should we do it?" [laughs].

The informants highlighted that this experience and knowledge broadened their perspective and understanding of interprofessional work. Furthermore, openness to new perspectives was described as an opportunity to develop and co-create education at the university. In co-creating this interprofessional academic course, the informants stressed that they learned about themselves and each other through reflection (individually and in groups) on the literature review, issues related to the process, and presentations regarding PCC by invited experts. The above-described relationship-building activities provided opportunities for partnership. According to the informants, collaboration helped broaden their perspectives in terms of the advantages and disadvantages of working with other professions, although it is easy to remain stuck in traditional habits and ways of thinking. However, they felt uncertain about each other's health professions in terms of the content and responsibilities of running the course. Interactions were described as complex as co-creation of the course required new subject knowledge (PCC) and new teaching methods (blended learning and flipped classroom) as well as interprofessional learning. Furthermore, they emphasized the 
importance of combining theory (personalism) and practice (health care), that is, learning from, with, and about each other.

However, now we had it and it was a great opportunity. In addition, I do not think we could have... because we represented several professions, I think we had to be there to get to know each other and each other's advantages and disadvantages. Now I do not mean as a person, but the professional category.

The informants highlighted that the opportunity to learn together contributed to personal growth in cooperation with others when problems were discussed from an interprofessional perspective. This was described in terms of life experiences.

And during this pilot project, cooperation with colleagues from the other professional categories meant a lot because we looked at different problems from the team's perspective, not just from our own professional role perspective.

3.2. Challenges of Managing Unfamiliar Knowledge. The category "Challenges of managing unfamiliar knowledge" is described in terms of challenges, openness, and commitment to achieving shared decision-making among the group of teachers. The informants were committed; however, they stressed difficulties in addressing philosophy because this was an unknown area of knowledge within the health-care context. This led to doubts regarding their own ability to develop a course in personcentred care. Moreover, the informants described the challenges of understanding the change in denomination from "patient" to "person," that is, in terms of both medical tasks and personal aspects (subject, not object), such as personal resources in everyday life. Furthermore, the informants highlighted the difficulties in applying the philosophy of person-centeredness to their everyday work (clinical and academic) because of the feeling that "I already do this." They described the frustration of managing unfamiliar knowledge, such as philosophical texts that present a diversity of perspectives. This frustration is illustrated in the following quote:

I think it is, now that I have extended myself or read a lot of literature on person-centeredness, it is obvious that we should work this way, but in the beginning, when we present our own efforts towards person-centeredness, I felt a little bit frustrated because it was very hard for me to understand the philosophy.... It may be because I'm not used to reading that kind of literature.... in education for physicians, we are very fact-oriented; it should be short and concise... and it was really hard to understand.

The informants expressed doubt that they would be able to understand person-centeredness because of the contrast between philosophy (subjective approach) and facts that are measurable and defined (objective approach), which contributed to their feelings of frustration. The teachers emphasized the significance of long-term experiences in countering doubts about their personal capacity to manage knowledge of a philosophical nature. Additionally, teaching and discussions among the teachers during the development of the course were stressed as valuable for helping them to understand philosophical texts regarding personcenteredness and the philosophy behind it. Through transparency and involvement in the project (We Educate Care), these discussions facilitated further reading of the literature within PCC:

Therefore, I felt that the group was a very permissive group. We were very open to each other. Or, how should I put it, it was very positive... Basically, I never heard someone picking on anyone, or something, or just saying, "God, this is crap". We had discussions all the time. In addition, then you rethink working with the syllabus. It was instructive because we had really different thoughts! And getting together to do something, all the work was useful.

The informants stated that the course content benefitted them by adding breadth and depth to their everyday work. Furthermore, they stressed the personal development they experienced by conquering a new field of knowledge with a philosophical grounding. The content of the course (PCC) was described as meaningful, having positive effects on practice, and a powerful approach to engaging in and developing health care. The informants also emphasized that the course content was interesting and instructive because it challenged their previous factual knowledge (scientific paradigm) and expanded it to include a wider horizon of understanding (hermeneutic paradigm). They described that this advanced understanding was frightening because insight into human complexity became visible and overwhelming. Feeling as if they needed to include patient resources aroused discomfort and seemed daunting in light of the limited resources of health services. They argued that the ethics of taking advantage of a patient's resources is unclear and presents a challenge for a health-care system with limited resources.

3.3. Wanting to Understand a New Educational Approach. The category "Wanting to understand a new educational approach" was described in terms of the content, process, and accountability involved in course development work. The informants described being involved in the project (We Educate Care) for more than a year as a process, a journey in stages. They noted the significance of the collaborative process in terms of reaching agreements through shared decision-making and common goals, which requires courage and innovation from all involved to allow them to learn from one another. In addition, the informants highlighted that consciousness creates opportunities for personal growth by encouraging sharing experiences during collaborative efforts to develop an interprofessional academic course in person-centred care. They highlighted the importance of 
a co-creative process that occurs in the settlement in a shared decision-making against common goal as

However, you are so into this that... I think that it will be on a piece of paper and "This I have done, check and check". .. It was actually a process over time; it was one of these great experiences for me.

In addition, the informants expressed satisfaction regarding the development of the course. They emphasized the importance of personal responsibility arising from the introduction of a new educational approach to improve the quality of health and social care. Balancing giving and controlling learning (between teacher and student), that is, creating enough space for individual responsibility, is necessary. The informants emphasized the need to pass responsibility to their students; however, they noted that this was difficult because of variations in teachers' experiences and knowledge. They stressed feeling uncertainty and ambiguity regarding the content and the use of educational approaches within the course, that is, who is going to do what? The informants emphasized the need for and significance of handing over responsibility to students; however, this does not always happen because of differences in experience and knowledge among teachers.

I think it was just that these, we applied these models, the methods. You should read or get to know the material before you attend group meetings; that way, it is possible that then when you met, you could, you got a deeper understanding and could spend time on concepts instead of clarifying them. This allow you to discuss and immerse yourself in the subject.

According to the informants, this process required courage and innovative thinking to allow the participants to learn from and with each other. Moreover, the process raised awareness, which created opportunities for personal development through the shared experience of the project (We Educate Care) as a new area of knowledge based on a philosophical approach. The informants stressed personcentred care as a powerful way of pursuing and developing health care. They said that the course content was interesting and instructive and challenged their previous factual knowledge (the natural paradigm) through greater understanding of a different framework (the hermeneutic paradigm).

Yes, I would have liked to start in a different way than reading the recommended chapters that we received. I read a little... I became a bit like, "Oh, what's in it for me?" So when you feel like you're in a hall of ice, then you go for defence instead.

\section{Discussion}

The aim of this study was to describe teachers' experiences in developing an interprofessional academic course in PCC at a Swedish university. The results focused on managing unfamiliar knowledge and understanding a new educational approach to co-create an interprofessional academic course. The work was characterized by listening to colleagues' experiences (narratives) regarding course development and content during collaboration and shared decision-making (partnerships) resulting in a curriculum, syllabus, study guidelines, and so on (documentation).

\subsection{Competence}

The result showed variations of knowledge regarding PCC that affected the understanding and implementation of person-centred care; these variations can be discussed in terms of Bloom's taxonomy [41]. The informants could repeat the content of person-centred care, as described by Ekman et al. [1], and were able to explain PCC by providing examples of how the approach may be expressed in daily practice. However, they described the difficulty in transforming and applying PCC to new contexts, such as an academic course. Staff who work interprofessionally do not always understand common/shared visions/decisionmaking. Lawlis, Anson, and Greenfield [42] stress that interprofessional learning improves competence by enabling processes through teamwork. In addition, [43] highlights that students' learning skills and health profession and organizational matters should be considered when developing and implementing new course content because of teachers' influences on learning.

Moreover, the development of knowledge and skills is illustrated as a progression from lower to higher levels of learning [41]. The current study shows that the informants reached Bloom's application level; they used core components in PCC, such as partnership (mutual respect for each other's expertise), narrative/patients' stories (shifting the focus from "what" to "who" and focusing on resources/capability), and documentation (mutual agreement and health plans based on patient and caregiver expertise), in real-life situations. However, the informants did not reach the point of synthesis (an ethical approach built on a philosophy), that is, the ability to combine a number of core components (PCC) into a new functional strategy, such as developing this academic course. The teachers seemed unable to envision future applications of the course, which presented an obstacle in teaching that focused on the "who" (person) instead of "what" (patient) approach that forms the philosophical basis of PCC [30]. Therefore, it is important that the university's management supports and enables employees to participate in the creation of common goals and visions by providing access to such resources as time and skills despite their heavy workload. Furthermore, it is necessary for teachers to collaborate within and between institutions at the faculty level through common teaching arenas that enable cooperation across institutional boundaries. The recruitment of employees for future collaboration should be based on their interest in and motivation to engage in teamwork in line with personalism, in which teachers are capable, responsible people (colleagues and managers) working expert-to-expert (competences) in shared decisionmaking processes (partnership) regarding a mutual syllabus 
(documentation) that involves different institute/faculties/students within the university. This conclusion can be viewed from the individual (teacher, student, and manager), group (teachers and health professionals/students), and organizational perspective (management at the micro, meso, and macro level) based on an ethical approach. Teachers' difficulties to understand the philosophy of person-centred care [30] could be related to their different professional paradigms (positivist and hermeneutic), that is, objective natural facts (quantitative methods) versus subjective lived experiences (qualitative methods). Traditionally, the education for some health-care professions such as medical doctors and physiotherapists is more firmly rooted in positivism, whereas, for example, nurses are more familiar with the hermeneutic paradigm. This can create friction when learning and educating about PCC, but also gives possibilities to bridge between professions specific contribution within a common PCC framework. However, beyond discussions on different paradigms and levels of evidence, the competence gained from PCC education is mainly practical and clinical. It encourages professionals to reflect, together, on the real and complex health and ill health of their patients-patients as persons with resources and needs. Objective and subjective perspectives broaden health professional's knowledge and skills within health care to involve each patient's resources, which develops and changes during life. The educational journey regarding philosophy of person-centred care starts at the universities professional's educational programme and develops with the team in health care [1]. All resources are included and the patient is the team leader due to partnership for improved well-being and patient safety.

4.2. Pedagogical Perspectives. The results show the difficulties the informants had acquiring new teaching methods. In terms of Bloom's taxonomy, the current study can be discussed in terms of facts, understanding, skills, and familiarization skills [41]. Teachers need knowledge regarding teaching methods to develop such educational skills as learning by doing [44]. By using suggestions and the intellectualization of ideas arising from the flipped classroom and blended learning methods[45], the current study elaborated on the development of these pedagogical tools, which took almost one and a half year and could be viewed as a journey. Historically, teachers have been somewhat unwilling to use digital communication tools (Facetime, chat, and Facebook), record lectures, and upload material and films to digital learning platforms [34]. However, the use of digital tools in education is common and is described as a supplemental resource that prepares students for digital citizenship; it is viewed as an inclusive tool that engages students and helps them retain the knowledge needed to be part of the 21st-century workforce. In addition, digital tools facilitate collaboration and idea sharing, peer reviews, and feedback from a teacher perspective [46]. However, the informants in the current study expressed their educational shortcomings, which is why continuing dialogue regarding pedagogical issues (and such content as PCC and digital tools) within the university is important for improving educational skills. In addition, long-lasting relationships among colleagues at the university are also significant when new educational actions are proposed to improve day-to-day lecturing [47].

Research has shown that students experience a gap between person-centred values and clinical reality [47], which is why new models/pedagogical perspectives are needed [48]. To improve education for health professionals, teachers need the pedagogical tools to incorporate workbased learning into collaborations among professions $[32,49]$. To understand the philosophical complexity of person-centred care, both teachers and students need to adapt new knowledge to different contexts with different colleagues to develop quality education [50].

4.3. Interprofessional Development. The result shows the significance of openness in the project group's work to develop an interprofessional academic course. Openness can be explained as the teachers' curiosity about one another, which can be viewed as engagement and a desire to explore and explain person-centred care through trust-making activities such as meetings (knowledge-based narrative), dialogue methodologies (pedagogy and philosophy), and collaboration (partnership) to complete a joint assignment (documentation), that is, developing an interprofessional academic course in PCC (syllabus). The openness and trust among the informants in this study indicate that high emotional trust increases people's ability to think within broader perspectives and act in a better way. Therefore, it is essential that future interprofessional projects be characterized by a high emotional climate based on joint decision-making. Research [32, 42, $43,48]$ demonstrates that relationships develop communication skills, increase learning, and develop professional identity, that is, increased responsibility. Joint decisions are based on individual and collective experiences (as teachers) among different health professions (nurses, physicians, occupational therapists, and physiotherapists). Moreover, joint decision-making involves challenges, opportunities, and obstacles arising from interprofessional teamwork. Interdisciplinary courses face differences in knowledge (philosophy, positivism, and hermeneutics), human opinion (object and subject), and social perception (structure and culture) within various institutions and limited experiences with cooperation across institutional boundaries. In addition, collaboration is a prioritized activity at the university level (meso) and at the institutional level (micro); furthermore, collaboration stimulates further cooperation across institutional boundaries, which creates conditions for better health care. One key aspect is the managerial perspective regarding facilitating the creation of joint courses at the university, and PCC is one content area that unifies professionals in different health fields and provides knowledge and skills regarding partnership, tools that increase teamwork to facilitate high-quality care.

4.4. Concluding Comments. Teachers experience three types of challenges when developing interprofessional academic courses in PCC. The first challenges are cognitive and are 
related to unfamiliarity with the field of person-centred care, selected educational activities, and teaching skills. Second, partnerships are delayed because teachers do not know their peers as people, faculty members, and/or practising clinicians. The third type of challenge is related to limited experience working with other teachers to develop academic courses and considering the structures and routines of different institutes. However, these three types of challenges also work as motivators; teachers have the necessary knowledge and experience to develop courses through synergies (educational and/or content skills/knowledge) that focused on resources and skills related to the first, second, and third types of challenges [30].

\section{Data Availability}

The data (written material/documentation, interviews) have not been made available because of confidential reasons due to confidential text and pictures regarding the developing processes. The data are available from the corresponding author upon request.

\section{Conflicts of Interest}

The authors declare that they have no conflicts of interest.

\section{Authors' Contributions}

KR, LD, IJ, and CW involved in study design. KR and CW collected the data, performed data analysis, and involved in manuscript preparation.

\section{Acknowledgments}

We thank the lecturers at Sahlgrenska Academy, University of Gothenburg, Sweden, who participated in the study and the University of Gothenburg Centre for Person-Centred Care (GPCC), Gothenburg, Sweden.

\section{References}

[1] I. Ekman, K. Swedberg, C. Taft et al., "Person-centered care-Ready for prime time," European Journal of Cardiovascular Nursing, vol. 10, no. 4, pp. 248-251, 2011.

[2] M. Brännström and K. Boman, "Effects of person-centred and integrated chronic heart failure and palliative home care. PREFER: a randomized controlled study," European Journal of Heart Failure, vol. 16, no. 10, pp. 1142-1151, 2014.

[3] L.-E. Olsson, J. Karlsson, and I. Ekman, "The integrated care pathway reduced the number of hospital days by half: a prospective comparative study of patients with acute hip fracture," Journal of Orthopaedic Surgery and Research, vol. 1, no. 1, p. 3, 2006.

[4] K. Ulin, L.-E. Olsson, A. Wolf, and I. Ekman, "Person-centred care-An approach that improves the discharge process," European Journal of Cardiovascular Nursing, vol. 15, no. 3, pp. e19-e26, 2016.

[5] C. Feldthusen, E. Dean, H. Forsblad-D'elia, and K. Mannerkorpi, "Effects of person-centered physical therapy on fatigue-related variables in persons with rheumatoid arthritis: a randomized controlled trial," Archives of Physical Medicine and Rehabilitation, vol. 97, no. 1, pp. 26-36, 2016.
[6] A. Fors, I. Ekman, C. Taft et al., "Person-centred care after acute coronary syndrome, from hospital to primary care-a randomised controlled trial," International Journal of Cardiology, vol. 187, pp. 693-699, 2015.

[7] K. Dudas, L.-E. Olsson, A. Wolf et al., "Uncertainty in illness among patients with chronic heart failure is less in person-centred care than in usual care," European Journal of Cardiovascular Nursing, vol. 12, no. 6, pp. 521-528, 2013.

[8] E. Hansson, I. Ekman, K. Swedberg et al., "Person-centred care for patients with chronic heart failure-a cost-utility analysis," European Journal of Cardiovascular Nursing, vol. 15, no. 4, pp. 276-284, 2015.

[9] L.-E. Olsson, E. Hansson, I. Ekman, and J. Karlsson, "A costeffectiveness study of a patient-centred integrated care pathway," Journal of Advanced Nursing, vol. 65, no. 8, pp. 1626-1635, 2009.

[10] I. Ekman, A. Wolf, L.-E. Olsson et al., "Effects of personcentred care in patients with chronic heart failure: the PCCHF study," European Heart Journal, vol. 33, no. 9, pp. 1112-1119, 2012.

[11] L.-E. Olsson, J. Karlsson, U. Berg, J. Karrholm, and E. Hansson, "Person-centred care compared with standardized care for patients undergoing total hip arthroplasty-a quasi-experimental study," Journal of Orthopaedic Surgery and Research, vol. 9, p. 95, 2014.

[12] D. Edvardsson, D. Fetherstonhaugh, L. Mcauliffe, R. Nay, and C. Chenco, "Job satisfaction amongst aged care staff: exploring the influence of person-centered care provision," International Psychogeriatrics, vol. 23, no. 8, pp. 1205-1212, 2011.

[13] D. Edvardsson, P. O. Sandman, and L. Borell, "Implementing national guidelines for person-centered care of people with dementia in residential aged care: effects on perceived personcenteredness, staff strain, and stress of conscience," International Psychogeriatrics, vol. 26, no. 8, pp. 1171-1179, 2014.

[14] K. Rosengren, "Person-centred care: a qualitative study on first line managers' experiences on its implementation," Health Services Management Research, vol. 29, no. 3, pp. 42-49, 2016.

[15] K. Sjögren, M. Lindkvist, P.-O. Sandman, K. Zingmark, and D. Edvardsson, "To what extent is the work environment of staff related to person-centred care? A cross-sectional study of residential aged care," Journal of Clinical Nursing, vol. 24, no. 9-10, pp. 1310-1319, 2015.

[16] L. Abraraw, A. Nilsson, and D. Edvardsson, "The influence of a person-centred psychosocial unit climate on satisfaction with care and work," Journal of Nursing Management, vol. 20, no. 3, pp. 319-325, 2012.

[17] T. Alharbi, L.-E. Olsson, I. Ekman, and E. Carlström, “The impact of organizational culture on the outcome of hospital care: after the implementation of person-centred care," Scandinavian Journal of Public Health, vol. 42, no. 1, pp. 104-110, 2014.

[18] L. Moore, N. Britten, D. Lydahl, Ö. Naldemirci, M. Elam, and A. Wolf, "Barriers and facilitators to the implementation of person-centred care in different healthcare contexts," Scandinavian Journal of Caring Sciences, vol. 31, no. 4, pp. 662673, 2017.

[19] A. Baldwin, J. Mills, M. Birks, and L. Budden, "Role modelling in undergraduate nursing education: an integrative literature review," Nurse Education Today, vol. 34, no. 6, pp. e18-e26, 2014. 
[20] M. Tagawa, "Effects of undergraduate medical students' individual attributes on perceptions of encounters with positive and negative role models," BMC Medical Education, vol. 16, no. 1, p. 164, 2016.

[21] K. Currie, S. Bannerman, V. Howatson et al., "'Stepping in' or 'stepping back': how first year nursing students begin to learn about person-centred care," Nurse Education Today, vol. 35, no. 1, pp. 239-244, 2015.

[22] M. Skaalvik, H. K. Normann, and N. Henriksen, "Student experiences in learning person-centred care of patients with Alzheimer's disease as perceived by nursing students and supervising nurses," Journal of Clinical Nursing, vol. 19, no. 17-18, pp. 2639-2648, 2010.

[23] S. Ananth and J. Wayne, "Patient-centeredness and caring in medical education," J Sci Healing, vol. 9, no. 2, pp. 116-117, 2013.

[24] A. Miles, J. E. Asbridge, and F. Caballero, "Towards a personcentered medical education: challenges and imperatives (I)," Educación Médica, vol. 16, no. 1, pp. 25-33, 2015.

[25] K. Theander, B. Wilde-Larsson, M. Carlsson et al., "Adjusting to future demands in healthcare: curriculum changes and nursing students' self-reported professional competence," Nurse Education Today, vol. 37, pp. 178-183, 2016.

[26] J. K. Schwind, G. M. Lindsay, S. Coffey, D. Morrison, and B. Mildon, "Opening the black box of person-centred care: an arts-informed narrative inquiry into mental health education and practice," Nurse Education Today, vol. 34, no. 8, pp. 1167-1171, 2014.

[27] J. Rosenzweig, A. Blaizot, N. Cougot et al., "Effect of a personcentered course on the empathic ability of dental students," Journal of Dental Education, vol. 80, no. 11, pp. 1337-1348, 2016.

[28] University of Gothenburg, 2018, https://www.gu.se/english/ about_the_university/?languageId $=100001 \&$ disableRedirect $=$ true\&returnUrl=http\%3A\%2F\%2Fwww.gu.se $\% 2$ Fomuniversitetet $\% 2 \mathrm{~F}$.

[29] Ruboni and A. W. C. Faculty, Development Practices in US Colleges and Universities, ProQuest Dissertations Publishing, Western Michigan University, Kalamazoo, MI, USA, 1994.

[30] P. Ricoeur, Oneself as Another, University press, Chicago, IL, USA, 1992.

[31] H. Owen, Open Space Technology: A User's Guide, BerrettKoehler Publishers, San Francisco, CA, USA, 2008.

[32] P. Hall, S. Brajtman, L. Weaver, P. A. Grassau, and L. Varpio, "Learning collaborative teamwork: an argument for incorporating the humanities," Journal of Interprofessional Care, vol. 28, no. 6, pp. 519-525, 2014.

[33] M. Lage, G. Platt, and M. Treglia, "Inverting the classroom: a gateway to creating an inclusive learning environment," Journal of Economic Education, vol. 31, no. 1, pp. 30-43, 2000.

[34] D. R. Garrison and H. Kanuka, "Blended learning: uncovering its transformative potential in higher education," Internet and Higher Education, vol. 7, no. 2, pp. 95-105, 2004.

[35] D. Polit and C. T. Beck, Nursing Research: Generating and Assessing Evidence for Nursing Practice, Wolters Kluwer Health/Lippincott Williams \& Wilkins cop., Philadelphia, PA, USA, 2012.

[36] J.-S. Armstrong, "The value of formal planning for strategic decisions-review of empirical research," Strategic Management Journal, vol. 3, no. 3, pp. 197-211, 1982.

[37] A. Tashakkori and C. Teddlie, Eds., Handbook of Mixed Methods in Social \& Behavioral Research, SAGE, Thousands Oaks, CA, USA, 2003.
[38] U. H. Graneheim and B. Lundman, "Qualitative content analysis in nursing research: concepts, procedures and measures' to achieve trustworthiness," Nurse Education Today, vol. 24, no. 2, pp. 105-112, 2004.

[39] Swedish Code of Statutes, "Hälso-och sjukvårdslagen, (health and medical services act)," SFS 1982:763/SFS 2014, p. 822, 1982, http://www.riksdagen.se/sv/Dokument-Lagar/Lagar/ Svenskforfattningssamling/Halso--och-sjukvardslag-1982_sfs1982-763/, in Swedish.

[40] Codex and Rules \& Guidelines for Research: The humanities and social sciences, 2017, http://www.codex.vr.se/en/ forskninghumsam.shtml.

[41] D. R. Krathwohl, “A revision of bloom's taxonomy: an overview," Theory into Practice, vol. 41, no. 4, pp. 212-218, 2002.

[42] T. R. Lawlis, J. Anson, and D. Greenfield, "Barriers and enablers that influence sustainable interprofessional education: a literature review," Journal of Interprofessional Care, vol. 28, no. 4, pp. 305-310, 2014.

[43] S. Reeves, J. Goldman, and I. Oandasan, "Key factors in planning and implementing interprofessional education in health care settings," Journal of Allied Health, vol. 36, no. 4, pp. 231-235, 2007.

[44] J. Dewey, How we Think: A Restatement of the Relation of Reflective Thinking to the Educative Process, Houghton Mifflin, Boston, MA, USA, 1998.

[45] J. Bernard, "The flipped classroom: fertile ground for nursing education research," International Journal of Nursing Education Scholarship, vol. 12, no. 1, pp. 33-43, 2015.

[46] E. J. Hallisey, High School Classroom Use of Digital Tools: A Case Study Approach, (Diss) Teachers College, Colombia University. ProQuest LLC, 2017, https://search.proquest.com/ docview/1910392120.

[47] K. Curtis, K. Horton, and P. Smith, "Student nurse socialisation in compassionate practice: a grounded theory study," Nurse Education Today, vol. 32, no. 7, pp. 790-795, 2012.

[48] I. K. Coulson, S. Galenza, S. Bratt, C. R. Foisy-Doll, and M. Haase, "A multi-dimensional analysis of person-centred collaborative practice for designing an educational curriculum in continuing care centres," Journal of Interprofessional Care, vol. 29, no. 1, pp. 71-72, 2015.

[49] S. G. Dean, R. J. Siegert, and W. Taylor, Interprofessional Rehabilitation: A Person-Centred Approach, John Wiley and Sons Ltd., Chichester: West Sussex, UK, 2012.

[50] Y. Cheung, S. Shah, and S. Muncer, "An exploratory investigation of undergraduate students' perceptions of cultural awareness," British Journal of Occupational Therapy, vol. 65, no. 12, pp. 543-550, 2002. 


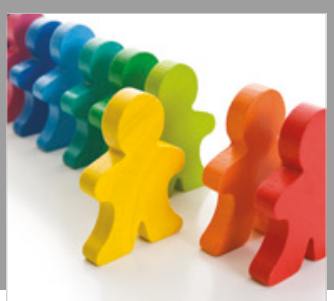

Autism

Research and Treatment
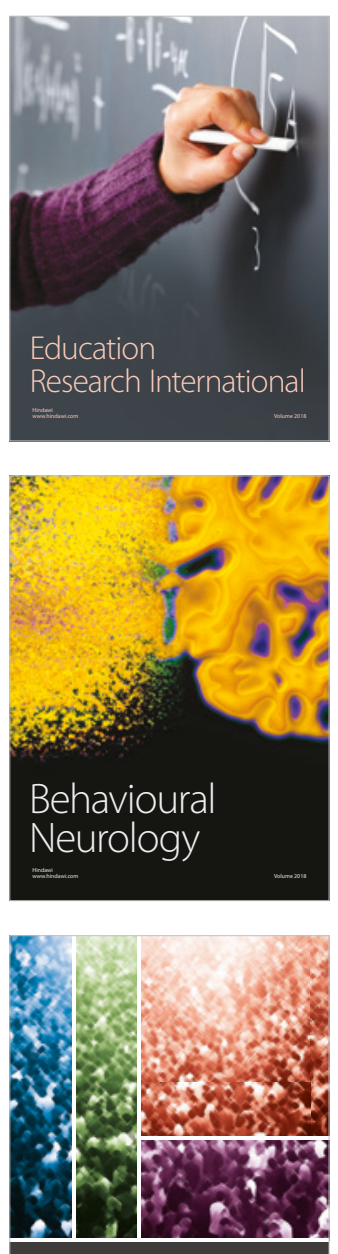

International Journal of

Population Research

$\underline{-m}$

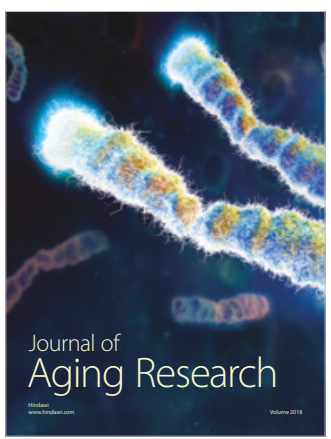

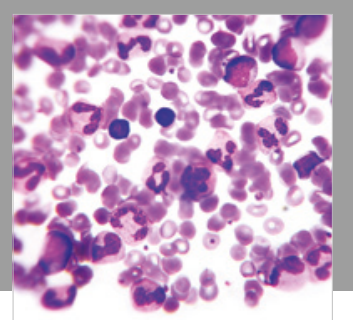

Pathology

Research International$$
=
$$

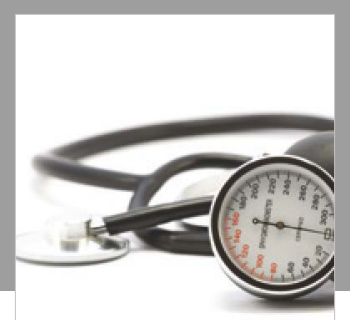

Nursing

Research and Practice

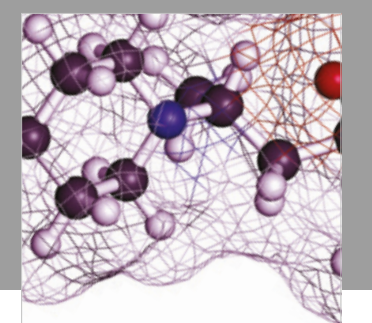

Pain

Research and Management

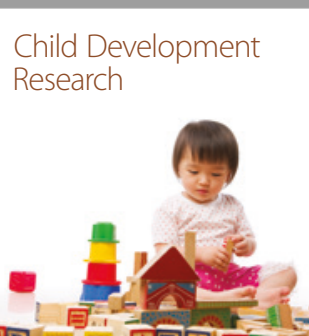

बाD

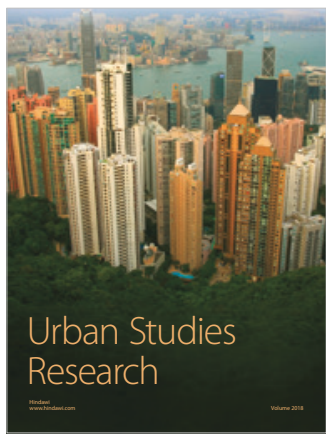

\section{Hindawi}

Submit your manuscripts at

www.hindawi.com
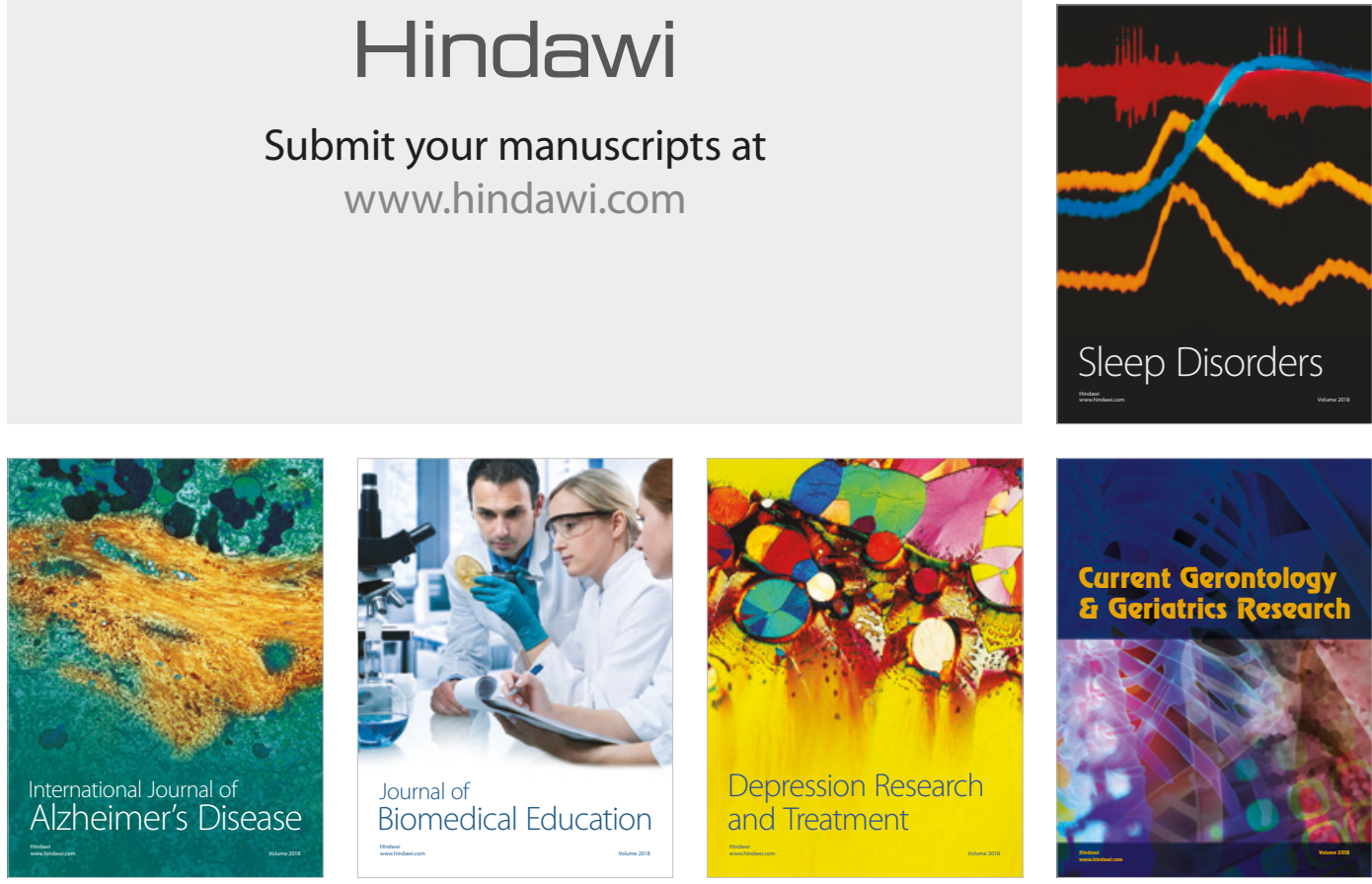

Journal of

Biomedical Education

$=$

smman

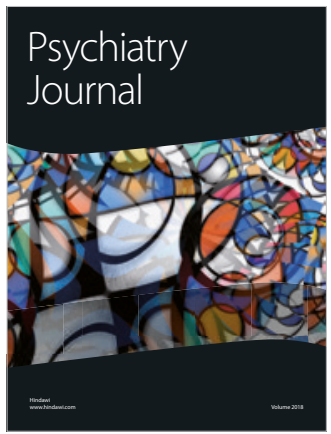

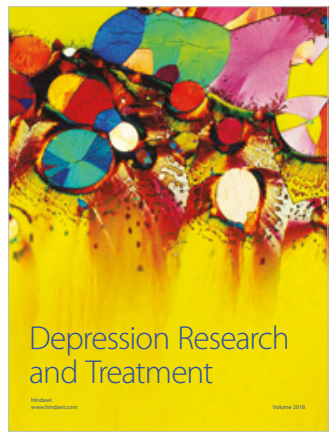
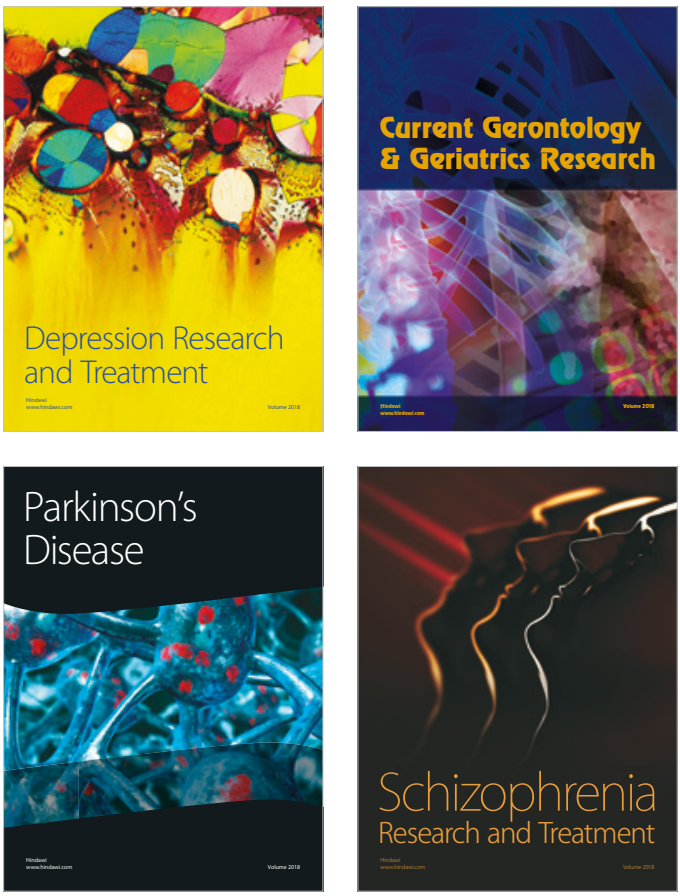